\title{
Risk-taking behaviours among fishermen in Morocco by the evaluation of "ordalique" functioning
}

\author{
Omar Laraqui ${ }^{1}$, Salwa Laraqui ${ }^{2,3}$, Nadia Manar ${ }^{2,3}$, \\ Mohammed Yassin Sahraoui ${ }^{3}$, Lamia Sebbar ${ }^{3}$, Tarik Ghailan ${ }^{3}$, \\ Frédéric Deschamps ${ }^{1}$, Chakib El Houssine Laraqui ${ }^{2,3}$ \\ ${ }^{1}$ Institut Universitaire De Médecine Et Santé Au Travail, Reims, France \\ ${ }^{2}$ Ecole Supérieure D'ingénierie De La Santé, Casablanca, Morocco \\ ${ }^{3}$ Association Marocaine De Recherche En Santé Au Travail, 39, Bd Lalla Yacout, Casablanca, Morocco
}

\begin{abstract}
Background: The aim was to investigate the potential fishermen's psychological functioning which induces risk-taking behaviours by evaluating the ordalique functioning.

Materials and methods: This cross-sectional epidemiological study was conducted in three ports of northern Morocco in 2016 and concerned 1413 traditional fishermen working in small embarkations and 1049 administrative staff working in the maritime sector on land. Both groups were male, comparable for age and educational level. The survey support was an individual questionnaire covering socio-demographic characteristics, toxic habits and ordalique functioning questionnaire (le questionnaire de fonctionnement ordalique, QFO). It is composed of 42 items and four dimensions which are evaluated: risk-taking, transgression, positive representation of risk-taking and believes.

Results: The prevalence of the ordalique behaviour and its four dimensions was significantly higher among traditional fishermen than administrative staff on land; $66.4 \%$ vs. 33.6\% ( $p<0.0001)$ for risk-taking, $65.2 \%$ vs. $34.8 \%(p<0.0001)$ for transgression, $60.4 \%$ vs. $39.6 \%$ ( $p<0.0001)$ for positive representation, $59.8 \%$ vs. $51.2 \%(p<0.0001)$ for believes. For all range ages, the prevalence of ordalique functioning was higher among fishermen than administrative staff on land. Among fishermen, the prevalence of the was significantly higher among the under 40 years old $(69.1 \%$ vs. $54.7 \%, p<0.0001)$. The prevalence of toxic habits among ordalique fishermen was significantly greater than no-ordalique ones: tobacco (54.5\% vs. $48.6 \%$, $p<0.035$ ), alcohol (42.8\% vs. $32.4 \%, p<0.0001$ ), cannabis ( $34.8 \%$ vs. $26.6 \%, p<0.0001$ ), psychotropic drugs $(13.8 \%$ vs. $10.4 \%, p<0.081)$ and a combination of toxic habits $(27.7 \%$ vs. $19.6 \%, p<0.0001)$.

Conclusions: Ordalique behaviour among fishermen may explain the partial failure of preventive measures in this sector. Risk-taking behaviours into account in the safety system could reduce occupational hazards in the fishery.
\end{abstract}

(Int Marit Health 2017; 68, 2: 83-89)

Key words: fishermen, risk-taking, behaviours, Morocco

\section{INTRODUCTION}

The human fragility at sea was formulated by the Greek philosopher of antiquity Anacharsis, who declared that "there are three sorts of people; those who are alive, those who are dead, and those who are at sea". The relentless struggle of traditional fishermen and the sea continues since centuries, and the maritime environment remains particularly dangerous to those who work there especially in developing countries [1].

In these countries, risk-taking behaviour among fishermen is still an observational epidemiological reality, associated with significant morbidity and mortality [2, 3]. These behaviours are defined as deliberate and repetitive risk-taking in hazardous situations which are very 
diverse and include the use of psychoactive substances, unprotected sexual intercourse, and work without technical prevention inducing numerous fatal occupational accidents $[4,5]$. Several studies carried out among traditional fishermen in Morocco suggest that they take many avoidable risks. These works focused on the consumption of addictive substances [6], knowledge, attitudes and practices to sexually transmitted infections [7], occupational stress [8], sleep disorders and alertness [9], and chronic obstructive pulmonary disease [10]. The profession of the fisherman is universally recognised as one of the most dangerous occupations. In France, in 2007, when there were 40 occupational accidents per 1000 employees on land, there were 121 occupational accidents per 1000 seafarers. The figures were even more eloquent when one observed the number of deaths by falling at sea or by sinking: a fisherman was about 44 times more likely to die at work than workers on land [2].

The 2014 record of occupational accidents in the maritime sector in France showed that the case fatality rate was five times higher than in the construction sector and that the majority of fatal accidents involved fishermen. The mortality rate for occupational accidents at sea was $1.18 \%$ compared with $0.03 \%$ on land; the frequency was almost 40 times greater [11]. The situation was more alarming in some regions of the world. The figures provided at the Third Spanish-French Maritime Medical Congress, held in Agadir in 2009, spoke for themselves: there were between 90 and 150 fatal occupational accidents per 100,000 fishermen in the world. In West Africa, this figure would be between 300 and 1000 and in South Africa it would be about 600 [2]. In the coastal fishery sector in Morocco, fatal occupational accidents accounted for $14.2 \%$ of occupational accidents in 2007 and 2008 [12]. Would fishermen have a psychological profile favouring risk-taking behaviours? Would these risk-taking acts be associated with ordalique behaviours? The aim of this survey was to investigate the potential fishermen's psychological functioning which induces risk-taking behaviours by evaluating the ordalique functioning.

\section{MATERIALS AND METHODS}

\section{SUBJECTS}

This observational and cross-sectional epidemiological study was conducted in three ports of northern Morocco (Tangier, Ras El Ma and Mdiq) throughout 2016. It concerned 1413 traditional fishermen working in small embarkations who were randomly selected from a complete list of 4627 (30.5\%) fishermen and 1049 administrative staff on land who included all people working in the maritime sector in these three ports. Both groups were exclusively males, older than 20 years with length of employment above one year. The complete lists were given by the presidents of the associations of fishermen of each port.

\section{THE QUESTIONNAIRE}

We used an individual and anonymised questionnaire including age, toxic habits and the ordalique functioning questionnaire (QFO). It is a tool to evaluate the ordalique behaviours [13]. It does not measure the intensity of existing ordalique functioning among a subject. It makes it possible to locate, among a subject, a possible "ordalique functioning", that is to say, the propensity of the subject to develop ordalique behaviour. Indeed, we can start from the principle that if a subject develops ordalique behaviours, it is because it possesses at bottom an "ordalique functioning" which underlies these behaviours. The QFO applies to both pathological and non-pathological subjects. It is composed of 42 items and four dimensions:

- Risk-taking (9 items): refers to the propensity of having dangerous activities (drugs use, risky sexuality, dangerous driving...);

- Positive presentation of risk-taking (9 items): refers to heroic representation of subjects who have risk-taking behaviours. This dimension mainly applies to narcissistic function of risk-taking;

- Transgression (12 items): refers to the subject's relation to law, rules, prohibitions and authorities and his tendency to have transgression behaviours;

- Believes (12 items): refers to various believes (luck, chance, God, etc.) and the implication of these believes in risk-taking behaviours.

A four-point Lickert scale (strongly agree, agree, disagree, strongly disagree) was chosen to keep the idea of the continuum of ordalique functioning. For the first and second dimensions, a score greater than or equal to 18 is considered positive. For the third and de fourth dimensions, a score greater than or equal to 24 is considered positive. A score equal to or greater than 84 confirms the ordalique behaviours.

\section{PROCEDURE OF THE STUDY}

We previously contacted the presidents of the associations of fishermen and the occupational physicians to explain the purpose of the study and to obtain their support and cooperation. The interviews took place within their occupational health units during the annual medical visit and lasted between 15 and 20 min for each person. The singular colloquium with each fisherman was carried out in confidentiality after informing them of the interest of our study. The questions were formulated orally, if 
Table 1. Characteristics of the total population

\begin{tabular}{llll}
\hline Characteristics & $\begin{array}{c}\text { Fishermen } \\
\text { (n= 1413) }\end{array}$ & $\begin{array}{l}\text { Administrative staff } \\
\text { (n= 1049) }\end{array}$ & P \\
\hline Age [years]: & & & 0.132 \\
$20-30$ & $434(30.7 \%)$ & $292(27.8 \%)$ & 0.49 \\
$31-40$ & $350(24.8 \%)$ & $310(29.6 \%)$ & 0.254 \\
$41-50$ & $437(30.9 \%)$ & $282(26.9 \%)$ & 0.152 \\
$>50$ & $192(13.6 \%)$ & $165(15.7 \%)$ & 0.151 \\
Average age & $36.2 \pm 1.2$ & $36.8 \pm 10.3$ & 0.0001 \\
Toxic habits: & & & 0.0001 \\
Tobacco & $739(52.3 \%)$ & $345(32.9 \%)$ & 0.0001 \\
Alcohol & $550(38.9 \%)$ & $211(20.1 \%)$ & 0.0001 \\
Cannabis & $448(31.7 \%)$ & $97(9.2 \%)$ & 0.0001 \\
Other psychotropic substances & $177(12.5 \%)$ & $55(5.2 \%)$ & $82(7.8 \%)$ \\
Poly-consumption & $348(24.6 \%)$ & &
\end{tabular}

Table 2. Prevalence of the ordalique behaviour and its dimensions among fishermen and among administrative staff on land

\begin{tabular}{llll}
\hline Dimensions & $\begin{array}{l}\text { Fishermen } \\
(\mathbf{n = 1 4 1 3})\end{array}$ & $\begin{array}{l}\text { Administrative staff } \\
(\mathbf{n = 1 0 4 9 )}\end{array}$ & P \\
\hline Risk-taking & $938(66.4 \%)$ & $352(33.6 \%)$ & 0.0001 \\
Positive presentation & $853(60.4 \%)$ & $415(39.6 \%)$ & 0.0001 \\
Transgression & $921(65.2 \%)$ & $365(34.8 \%)$ & 0.0001 \\
Believes & $845(59.8 \%)$ & $538(51.2 \%)$ & 0.0001 \\
Ordalique behaviour & $886(62.7 \%)$ & $496(47.3 \%)$ & 0.0001
\end{tabular}

necessary translated in Arabic dialect. We have said that their answers do not reflect their true behaviour but rather what they would like to do in sincerity and that of course their religion and education prevents them from doing so. The fishermen and administrative stuff answered the questionnaire without difficulty and with enthusiasm.

\section{STATISTICAL ANALYSIS}

The statistical analysis were performed using the SPSS version 11.5 software package. The differences between groups were compared using t tests for continuous variables and $\chi^{2}$ tests for categorical ones. The statistical level of significance was established at $5 \%$.

\section{RESULTS}

The average age was of $36.2 \pm 10.2$ years for fishermen and of $36.8 \pm 10.3$ years for administrative staff on land; the difference was not significant ( $p=0.151$ ). $55.5 \%$ of fishermen were under 40 years old vs. $57.4 \%$ for administrative staff on land; the difference was not significant $(p=0.368)$. The prevalence of all toxic habits was signifi- cantly higher among fishermen than among administrative staff on land (Table 1).

The prevalence of the ordalique behaviours and its four dimensions was significantly greater among fishermen than among administrative staff on land (Table 2).

For all range ages, the prevalence of the ordalique behaviour was significantly higher among fishermen than among administrative staff on land.

The average age of the ordalique fishermen was significantly lower than the ordalique administrative staff on land (34.8 \pm 9.6 years vs. $36.1 \pm 10.3$ years, $p=0.019$ ) (Table 3 ).

Among fishermen, the prevalence of the ordalique behaviours was significantly higher among those under 40 years old (69.1\% vs. $54.7 \%, p=0.0001$ ) (Table 3 ).

The prevalence of all toxic habits was significantly higher among ordalique fishermen than among ordalique administrative staff on land (Table 4).

Among fishermen, the prevalence of toxic habits was significantly higher among ordalique than among no ordalique for tobacco, alcohol, cannabis and the poly-consumption. For the consumption of other psychotropic substances, the difference was not significant (Table 5). 
Table 3. Prevalence of the ordalique behaviours by age among fishermen and among administrative staff on land

\begin{tabular}{llll}
\hline Age [years] & $\begin{array}{l}\text { Fishermen } \\
(\mathbf{n}=\mathbf{8 8 6} ; \mathbf{6 2 . 7} \%)\end{array}$ & $\begin{array}{l}\text { Administrative staff } \\
\text { (n= 496; 47.3\%) }\end{array}$ & P \\
\hline $20-30$ & $309 / 434(71.2 \%)$ & $156 / 292(53.4 \%)$ & 0.0001 \\
$31-40$ & $233 / 350(66.6 \%)$ & $165 / 310(53.2 \%)$ & 0.0001 \\
$41-50$ & $245 / 437(56.1 \%)$ & $111 / 282(39.4 \%)$ & 0.0001 \\
$>50$ & $99 / 192(51.6 \%)$ & $64 / 165(38.8 \%)$ & 0.021 \\
$<40$ & $542 / 784(69.1 \%)$ & $321 / 622(51.5 \%)$ & 0.0001 \\
$\geq 40$ & $344 / 629(54.7 \%)$ & $175 / 447(39.1 \%)$ & 0.0001 \\
Average age & $34.8 \pm 9.6$ & $36.1 \pm 10.3$ & 0.019
\end{tabular}

Table 4. Prevalence of toxic habits among ordalique fishermen and ordalique administrative staff on land

\begin{tabular}{llll}
\hline Toxic substances & $\begin{array}{l}\text { Fishermen } \\
\text { (n= 886; 62.7\%) }\end{array}$ & $\begin{array}{l}\text { Administrative staff } \\
\text { (n= 496; 47.3\%) }\end{array}$ & P \\
\hline Tobacco & $483(54.5 \%)$ & $196(39.5 \%)$ & 0.0001 \\
Alcohol & $379(42.8 \%)$ & $142(28.6 \%)$ & 0.0001 \\
Cannabis & $308(34.8 \%)$ & $78(15.7 \%)$ & 0.0001 \\
Other psychotropic substances & $122(13.8 \%)$ & $36(7.3 \%)$ & 0.0001 \\
Poly-consumption & $245(27.7 \%)$ & $51(10.3 \%)$ & 0.0001
\end{tabular}

Table 5. Prevalence of toxic habits among ordalique and no-ordalique fishermen

\begin{tabular}{llll}
\hline Toxic substances & $\begin{array}{l}\text { Ordalique behavior } \\
\text { (n= 886; 62.7\%) }\end{array}$ & $\begin{array}{l}\text { No ordalique behavior } \\
\text { (n= 527; 47.3\%) }\end{array}$ & P \\
\hline Tobacco & $483(54.5 \%)$ & $256(48.6 \%)$ & 0.035 \\
Alcohol & $379(42.8 \%)$ & $171(32.4 \%)$ & 0.0001 \\
Cannabis & $308(34.8 \%)$ & $140(26.6 \%)$ & 0.002 \\
Other psychotropic substances & $122(13.8 \%)$ & $55(10.4 \%)$ & 0.081 \\
Poly-consumption & $245(27.7 \%)$ & $103(19.6 \%)$ & 0.0001
\end{tabular}

\section{DISCUSSION}

\section{CONCEPTS}

Several questions might be raised. Can risky professions such as fisheries select subjects with risk-taking behaviour? Do some not choose their profession for the intrinsic existence of the danger that it entails? Hence a selection of subjects with particular personality? Do fishermen have a psychological functioning inducing unsafety acts? How to explain the many unsafe acts?

Several theories are possible, including defensive ideology [14], addictive disorder to danger [5, 15] and the psychopathological model of risk-taking behaviours or ordalique functioning $[3,13,16]$.

The defensive ideology of profession [14]. Fishermen are well aware of the risks involved. The danger to them is often of a collective nature. The risk of danger generates an internalised sense of fear. Fishermen frequently resort to defensive mechanisms such as denial, trivialisation or risk minimisation. They develop collective strategies, defence against fear, to protect them from psychological suffering.

This pseudo-unconsciousness of danger results in attitudes of ignoring risk, transgression of rules and risk-taking. The collective character is shared by all fishermen. The functional value of the model in relation to productivity results in a cohesion of the group. The defensive ideology of profession would result in a selection of subjects with a particular psychological functioning "the offense at one level or another is not only inevitable but even more necessary for the proper functioning of the organisation".

Addictive disorder to danger $[5,15]$. Some psychiatrists exclude occupational activities and working conditions from 
addictive disorder to danger. For them, risk behaviours translate into "deliberate and repetitive engagement in dangerous situations, for oneself and possibly others, but actively sought for the tried and tested of strong feelings, of play with danger and often of death". The person is looking for danger to be able to dominate it instead of undergoing it. The confrontation with danger is a real source of excitement and attraction with the appearance of a certain degree of dependence. Several studies show that playing a dangerous sport has a direct influence on the emotional state of athletes. Affect that does not equate only relief but an "extraordinary experienced". Notwithstanding the unique qualities of these sports, it is likely that some subclinical individual characteristics such as sensation seeking, emotional-behavioural deregulation can promote a self-reinforcement of these practices or even facilitated the installation of an addictive tendency. Risk and intense sensation are also at the heart of dangerous games. Four points seem to motivate these practices: risk-taking, intensity, loss of consciousness, and the "wake survival".

Ordalique functioning model $[3,13,16]$. Ordalique behaviour is defined as a repetitive behaviour for the taking vital risks. This psychopathological model of risk behaviour "is tendency for a subject to engage himself more or less frequently in life-threatening trials, the outcome of which must not be obviously predictable, by placing himself in the hands of God, chance, destiny or luck". The model has four major dimensions:

- Risk-taking dimension refers to the propensity of the subject to engage in dangerous activities (drugs use, risky sexuality, dangerous driving...);

- Positive vision of risk-taking dimension refers to heroic representation of subjects who have risk-taking behaviours. This dimension mainly applies to narcissistic function of risk-taking; rewarding for the actor and in the eyes of others;

- Transgression dimension refers to the subject's relation to law, rules, prohibitions and authorities and his tendency to have transgression behaviours;

- Believes dimension refers to various believes (luck, chance, God, etc.) and the implication of these believes in risk-taking behaviours. It evaluates the person's believes about luck, superstition and divine protection.

\section{ANALYSIS OF OUR RESULTS}

The relentless struggle between the artisanal fishermen and the sea for centuries continues and the maritime environment remains particularly accidental. The dangerousness and complexity of this profession is explained by an arduous and laborious activity with irregular rhythms and countless constraints requiring a sustained degree of atten- tion. In the study conducted in Brittany [3], no significant difference ( $p=0.971$ ) was observed between seafarers (30\%) and non-marine employees (31.3\%) for the risk-taking dimension. In our study, a significant difference was found between seafarers and administrative staff on land $(66.4 \%$ vs. $33.6 \%, p=0.0001$ ).

This type of profile might justify, in part, the occurrence of numerous accidents at sea. We could suppose that our fishermen had risky behaviours that could be explained in part by the obsolescence of the equipment, the age and the mechanical state of the boats and the geographical and meteorological peculiarities of the region which required more attention and vigilance. The Strait of Gibraltar is one of the largest maritime crossroads in the world. It is known by its intense international circulation and its violent periodic winds of which the most powerful is the Sirocco "chergui".

According to Jégaden et al. [3], the human factor was more often linked to behaviour that was unsuitable for the situation itself and often directly linked to meteorological hazards or mechanical failures. However, risk-taking was, according to Lyng [17], the reaction to a sense of alienation at work. Indeed, our fishermen were completely absorbed by their work and did not own the means of this work and did not benefit from production. They had no leisure outside the simple purely physiological interruptions for sleep and meals.

They suffered of socio-economic constraints (low income, job insecurity, distance from their families, etc.), which were sources of job dissatisfaction and anxiety. A specific relationship exists between risk-taking and ill-being $[18,19]$. Risk-taking behaviours are often exacerbated by illiteracy ( $21.3 \%$ of our fishermen are illiterate), inadequate training and safety culture, fatigue, stress, sleepiness, decreased vigilance can alter judgment, attention or physical conditions. These various causes play, of course, an indisputable and likely major role in the occurrence of numerous accidents among fishermen.

The expansion of small-scale fishing entails numerous tragedies every year, most often linked to the failure to respect the most basic rules of safety. In our study, we found a significant difference in the transgression and positive vision between the fishermen and the administrative staff on land $(65.2 \%$ vs. $34.8 \%, p=0.0001$ and $60.4 \%$ vs. $39.6 \%$, $p=0.0001$ ). According to Jégaden et al. [3], the fishing profession led to a certain selection of subjects with a particular characteristic. Most fishermen did not deliberately seek hazard, but if there was a risk, they took it in disregard of safety rules (it is their transgressive side: $40 \%$ vs. $25.2 \%$, $p=0.046$ ) and they were proud of it (it is their narcissistic side: $53.3 \%$ vs. $56.2 \%, p=0.799$ ) [3].

Death at sea is a particular case that does not correspond to any of the schemas to which the human being is used to ashore. It is partly due to the collective representa- 
tions of the dangerousness of the sea but also to the lack of knowledge of the maritime environment. The prevalence of the "believes" dimension was also higher among our fishermen than administrative staff on land $(59.8 \%$ vs. $51.2 \%, p=0.0001$ ). However, both groups had significant prevalence. So, we could classify them in so-called ordalique functioning. On land, these behaviours affected a proportion of the general population and resulted in a very high prevalence of road accidents in Morocco, the situation was dramatic and roads were among the deadliest in the world. According to the decade report of the Ministry of Equipment and Transport, a vehicle killed 16 times more than in Sweden and 9.7 times more than in France. Failure to comply with the Highway Code was the main accident factor recognised by road safety officials [20]. In Brittany, the prevalence of the "believes" dimension was low and did not differ between seafarers and non-marine employees ( $37.7 \%$ vs. $44.1 \%, p=0.454)$. This result surprised the investigators because maritime culture in France largely refers to religious beliefs linked to divine protection [3]. This is even truer in the more practicing Moroccan population. The fear of death at sea finds in our regions a double cultural and religious origin. On the cultural level, in both countries, the families cannot live their mourning fully (burial, contemplation...). The specificity of the relationship to death at sea must also be taken into account in accordance with religious practices.

Although in the book of Gerard Guyon on Catholicism in France published in 2015, religious believes have become increasingly rare, if non-existent [21]. For Christians, the fears surrounding the prospect of death at sea deprive them of the ritual of the last social act of the believer. To perish at sea condemns obtaining neither the rest of the body nor that of the soul, without receiving the spiritual support of a priest. If Christianity does not instigate fears about the absence of burial, it is clear that the ritual of funerals and the concern to give every man a burial have a decisive role in the excessive fear of death at sea. In the mental representation of sailors, the body of a person drowned and abandoned in the sea is condemned not to enjoy the rest of a dignified burial [2].

Islam allows a deceased person a ship if the land is far away, to benefit from the funeral rituals exactly as if it is on land and then to be ballasted and thrown into the sea. According to the prophet's words "The shipwrecked believer is one of the martyrs and his place is in heaven" (hadith). On land, burial is considered a right for the dead and an obligation for his community. However, funerary monuments are not allowed but only tolerated to avoid the worship of the dead and the creation of idols. Hadith: "Leave no emerging tomb except by flattening it". On the other hand, earthly life is only a stage of existence; "an obligatory and transitory state", towards the "last life". Death is therefore a rebirth, a passage to another world better for believers. It is also a divine fate in the creation of the human being: "When their time comes, they can neither delay it nor advance it" (Quran 16/61) [22].

\section{CONCLUSIONS}

Our fishermen had some characteristics of the ordalique functioning with risk-taking behaviour. They could have an attraction for the taking of transgressive risks, a rewarding vision of this risk-taking and a belief in divine protection with a degree of fatality. These behaviours could be the cause of the failure of individual or collective security measures. Taking into account the behavioural factors in the health and safety systems would allow a reduction of occupational accidents in this sector. Our fishermen have to benefit from an appropriate environment to their well-being, training in maritime safety and helping them to modify the cultural and religious representations firmly anchored in their mentality.

\section{REFERENCES}

1. Recanati H. Les vivants, les morts et ceux qui vont sur la mer. La Rochelle, France, La découvrance. 2015.

2. Kowalski JM. JM. Les marins et la mort. Actualité d'un mythe. La Revue maritime. 2011; 492: 90-102.

3. Jégaden D, Lemoine C, Paris P, Landrin D, Eusen Y, Loddé B, Dewitte JD. Les marins-pêcheurs ont-ils un profil psychologique particulier conduisant à des conduites à risques ? Colloque international ErgoMare, 5-6-7 octobre 2006, Lorient, France.

4. Eusen Y. Addictions chez les marins: alcool, tabac, drogues " Traité de Médecine maritime. Lavoisier. 2015: 113-117.

5. Michel G, Bernadet S, Aubron V, et al. Des conduites à risques aux assuétudes comportementales: le trouble addictif au danger. Psychologie Française. 2010; 55(4): 341-353, doi: 10.1016/j. psfr.2010.07.003.

6. Laraqui O, Laraqui S, Manar N, et al. Prevalence of consumption of addictive substances amongst Moroccan fishermen. Int Marit Health. 2017; 68(1): 19-25, doi: 10.5603/IMH.2017.0004, indexed in Pubmed: 28357832.

7. Laraqui S, Laraqui O, Manar N, et al. The assessment of seafarers' knowledge, attitudes and practices related to STI/HIV/AIDS in northern Morocco. Int Marit Health. 2017; 68(1): 26-30, doi: 10.5603/ IMH.2017.0005, indexed in Pubmed: 28357833.

8. Laraqui O, Laraqui S, Caubet A, et al. Evaluation du stress professionnel chez les gens de mer à Tanger. Medicina Maritima. 2010; 10(1): 38-58.

9. Ghailan T, Hamdouche I, Bennouna A, et al. Evaluation des troubles du sommeil chez les pêcheurs de Tanger. Medicina Maritima. 2009; 9: 2.

10. Laraqui O, Manar N, Ghailan T, et al. Dépistage de la bronchopneumopathie chronique obstructive et qualité de vie dans un échantillon de gens de mer à Kénitra. Medicina Maritima. 2014; 14: 1.

11. Accidents du travail et maladies professionnelles maritimes en France, Bilan 2014. http://www.developpement-durable.gouv.fr/ Accidents-du-travail-et-maladies,46659.html. 
12. Ghailan T, Caubet A, Verger $C$, et al. Prévalence des accidents du travail dans le secteur de la pêche côtière au Maroc. Actes des 26èmes journées internationales méditerranéennes de médecine de travail. Rennes. 2011.

13. Cardénal M, Sztulman H, Schmitt L. Le questionnaire de fonctionnement ordalique (QFO): premiers éléments de validation et résultats préliminaires chez des toxicomanes et des anorexiques. Annales Médico-psychologiques, revue psychiatrique. 2007; 165(10): 703-713, doi:10.1016/j.amp.2005.10.004.

14. Dejours C. Travail, usure mentale. Bayard éditions, Paris 1993: 120.

15. Adès J, Lejoyeux M. Conduites de risque. EMC - Psychiatrie. 2004; 1(3): 201-215, doi: 10.1016/j.emcps.2004.03.003.

16. Valleur M. Les addictions sans drogue et les conduites ordaliques. L'Information Psychiatrique. 2005; 81: 423-428.
17. Lyng S. Edgework: a social psychological analysis of voluntary risk taking. Am J Sociol. 1990; 95(4): 851-886, doi: 10.1086/229379.

18. Le Breton D. Conduites à risque, . Paris, PUF. 2002: 111.

19. Peretti-Watel $P$. Interprétation et quantification des prises de risque délibérées. Cahiers internationaux de sociologie. 2003; 114(1): 125-141, doi:10.3917/cis.114.0125.

20. Laraqui O, Laraqui S, Tripodi D, et al. Évaluation de la vigilance chez les conducteurs professionnels de poids lourds à Casablanca. Archives des Maladies Professionnelles et de l'Environnement. 2008; 69(4): 574-585, doi: 10.1016/j.admp.2008.02.018.

21. Guyon G. Catholicisme en France, Essai sur un état des lieux. Poitiers, Dominique Martin Morin (DMM). 2015: 310.

22. Boutaleb A. Pour mieux comprendre I'Islam. Casablanca, Afrique Orient, $2002: 318$. 